\title{
Assessment of the risk factors and functional outcome of delirium in acute stroke
}

\author{
A. M. Zaitoun, Dorriya Abdel Fattah Elsayed, Bothina M. Ramadan ${ }^{*}$ and Hanan Ahmed Abdel Gaffar
}

\begin{abstract}
Background: Post stroke delirium is a multifactorial life-threatening process, still poorly understood. The aim of the study was to identify the risk factors associated with the development of delirium in acute stroke patients and detection of the effect of delirium on the short-term prognosis of acute stroke patients.

Patients and methods: This study was carried on 74 acute stroke patients, 40 males (54.1\%) and 34 females (45.9\%). Full general and neurological examination was performed to all patients. Full routine laboratory investigation and computed tomography scan and/or magnetic resonance imaging of the brain were done.

Results: The patients were divided into two groups: 15 patients with delirium (group I) and 59 patients without delirium (group II). The incidence of delirium was higher among patients with older age $(P=0.002)$. There was no statistically significant relationship between incidence of delirium and sex of patients $(P=0.52)$. The delirium patients had significantly higher National Institutes of Health Stroke Scale (NIHSS) $(P=0.001)$ and lower Glasgow Coma Scale (GSC) $(P=0.001)$ at admission. They also had high mortality $(P=0.017)$ and lower Barthel Index $(B I)$, and these results were statistically $(P=0.001)$ significantly.
\end{abstract}

Conclusion: Post stroke delirium was associated with old age, higher NIHSS at admission, intracerebral hemorrhage, and higher long-term mortality.

Keywords: Stroke, Delirium, Prognosis, Outcome

\section{Introduction}

The term stroke encompasses a wide diversity of vascular diseases of the central nervous system. Stroke is considered the second most common cause of death and the seventh leading cause of disability worldwide [1].

Delirium is defined by the American Psychiatric Association as an acute, transient disorder of cognition and consciousness with fluctuating intensity [2]. Delirium may be hyperactive which is accompanied by overt psychotic symptoms and agitation, hypoactive which is characterized by sedation, or mixed (i.e., both hypoactive and hyperactive). The hypoactive type can often be undetected or misdiagnosed as depression [3]. If delirium is not detected on admission to a hospital, then the risk of death may be increased eightfold [4].

\footnotetext{
* Correspondence: drbothinaramadan@gmail.com

Department of Neurology, Zagazig University, Zagazig, Shakia, Egypt
}

Delirium is associated with higher mortality, morbidity, and longer in-patient stay, and as a consequence, it causes more strain on nursing resources [5].

New prospective studies are needed to identify patients at risk of developing delirium for future trials of preventive strategies [6].

This study aims to identify the risk factors associated with the development of delirium and to detect its effect on the short-term prognosis of acute stroke patients.

\section{Patients and methods}

This study was done at Intensive Care and Stroke Units, Neurology Department, Zagazig University Hospitals, during the period from June 2015 to December 2015. This study was prospectively conducted on 74 patients presented with acute stroke. The studied patients were divided into two groups:

Group I: stroke patients with delirium 
Group II: stroke patients without delirium

Written informed consent was obtained from all patients or written consent from a relative.

The patient's age was $\geq 30$ years old. The acute stroke patients included patients with cerebral infarction, intracerebral hemorrhage and subarachnoid hemorrhage.

We excluded all patients with transient ischemic attacks, history of severe head trauma, cerebral venous sinus thrombosis, brain tumors, history of psychosis, severe dementia prior to the onset of stroke, history of anticholinergic medication intake before stroke, and aphasia; comatose patients; and patients with hepatic impairment, renal impairment, or respiratory failure.

All patients were subjected to the following:

- Detailed medical history with special attention to past medical history obtained from the patients or their relatives to establish the presence of any risk factor such as hypertension (HTN), diabetes mellitus (DM), smoking, cardiac diseases, and other risk factors such as previous transient ischemic attacks and previous ischemic stroke

- Complete general examination

- Thorough neurological examination: all patients in our study were subjected to full neurological examination including:

- Mini Mental State Examination, MMSE [7]

- National Institutes of Health Stroke Scale (NIHSS): the initial assessment of stroke severity was evaluated by using NIHSS [8], within the first $24 \mathrm{~h}$ of stroke onset at admission. This standardized neurological scale is a well-validated tool for assessing initial stroke severity [9]

Ischemic stroke subtypes were classified according to TOAST (Trial of Org 10172 in Acute Stroke Treatment) criteria [10], into large-artery arteriosclerosis, small-artery occlusion, cardio-embolism, undetermined etiology, and other undetermined etiology.

The clinical ischemic stroke syndromes were determined by applying the criteria of the Oxfordshire Community Stroke Project: total anterior circulation infarction (TACI), partial anterior circulation infarction (PACI), lacunar infarction (LACI), and posterior circulation infarction (POCI) [11].

Screening for delirium within 3 days after stroke was based on the criteria from Diagnostic and Statistical Manual of Mental Disorders, 4th Edition, DSM-IV [12].

Full routine laboratory investigations at admission were conducted.

Computed tomography (CT) scan or MRI of the brain was done: follow-up of patients after 1 month radiologically with brain CT, clinically using NIHSS and the
Barthel Index [13] to assess the patient's functional outcome and also mortality.

\section{Statistical analysis}

The data were tabulated and statistically analyzed using SPSS version 14.00 software package [14]. The results obtained were analyzed by use of the standard statistical parameters, i.e., means, standard deviation (SD), Student's $T$ test, and chi-square $\left(\chi^{2}\right)$ test. A value of $P<0.05$ was considered statistically significant.

\section{Results}

This cohort study was conducted on 74 stroke patients (40 male, 54.1\%; 34 female $45.9 \%$ ) who were admitted in Intensive Care and Stroke Units, Neurology Department, Zagazig University. Their mean age $( \pm$ SD) was 60.7 ( \pm $11.5)$ years with a range of 30-93 years. The results of our study were statistically analyzed, tabulated, and summarized as follows:

The demographic data and medical history of the studied patients were showed in Table 1.

The incidence of delirium was higher among patients with older age, and these results were statistically significant. There was no statistically significant difference between incidence of delirium and sex of patients, presence of medical history of hypertension, diabetes mellitus, smoking, previous TIA, and cardiac diseases. The incidence of delirium was higher among patients with lower GCS and higher NIHSS at admission, and these results were statistically significant (Table 2).

There was statistically significant difference between the incidence of delirium and patients having intracerebral hemorrhage (Table 3), cardio-embolic ischemic stroke (Table 4), and ischemic stroke with TACI and right hemispheric lesion (Table 5).

Table 1 The demographic data and medical history of the studied patients

\begin{tabular}{|c|c|c|}
\hline Age, years $(M \pm S D)$ & $60.7 \pm 11.5$ & Range (30-93) \\
\hline \multicolumn{3}{|l|}{ Sex, $N(\%)$} \\
\hline - Male & 40 & $54.1 \%$ \\
\hline - Female & 34 & $45.9 \%$ \\
\hline \multicolumn{3}{|l|}{ Medical history, N (\%) } \\
\hline - Hypertension & 53 & $71.6 \%$ \\
\hline - Diabetes mellitus & 30 & $40.5 \%$ \\
\hline - Smoking & 27 & $36.5 \%$ \\
\hline - Previous stroke & 15 & $20.3 \%$ \\
\hline - TIA & 9 & $12.2 \%$ \\
\hline - Cardiac disease & 23 & $31.1 \%$ \\
\hline
\end{tabular}

$M$ mean, SD standard deviation, TIA transient ischemic attack 
Table 2 Delirium frequency according to demographic data, medical history, and clinical examination of stroke patients

\begin{tabular}{|c|c|c|c|c|}
\hline \multirow[t]{2}{*}{ Variables } & \multicolumn{2}{|l|}{ Delirium } & \multirow{2}{*}{$\begin{array}{l}\text { Test of } \\
\text { significance }\end{array}$} & \multirow[t]{2}{*}{ P } \\
\hline & $\begin{array}{l}\text { Present } \\
N=15\end{array}$ & $\begin{array}{l}\text { Absent } \\
N=59\end{array}$ & & \\
\hline \multicolumn{5}{|c|}{ Age (years) } \\
\hline$M \pm S D$ & $68.6 \pm 9.6$ & $58.8 \pm 11.2$ & $T=3.11$ & $0.002^{*}$ \\
\hline Range & $53-93$ & $30-80$ & & \\
\hline \multicolumn{5}{|c|}{ Sex } \\
\hline Male, N (\%) & $7(46.7 \%)$ & $33(55.9 \%)$ & $x^{2}=0.41$ & 0.52 \\
\hline Female, $N(\%)$ & $8(53.3 \%)$ & $26(44.1 \%)$ & & \\
\hline \multicolumn{5}{|l|}{ Medical history, N (\%) } \\
\hline - Hypertension & $12(80 \%)$ & $41(69.5 \%)$ & $x^{2}=0.24$ & 0.62 \\
\hline - Diabetes mellitus & $5(33.3 \%)$ & $25(42.4 \%)$ & $x^{2}=0.41$ & 0.52 \\
\hline - Smoking & $4(26.7 \%)$ & $23(39 \%)$ & $x^{2}=0.78$ & 0.37 \\
\hline - Previous stroke & $2(13.3 \%)$ & $13(2213)$ & $x^{2}=0.15$ & 0.69 \\
\hline$-\mathrm{TIA}$ & $2(13.3 \%)$ & $7(11.9 \%)$ & $x^{2}=0.08$ & 0.77 \\
\hline - Cardiac disease & $7(46.7 \%)$ & $16(27.1 \%)$ & $x^{2}=1.32$ & 0.25 \\
\hline \multicolumn{5}{|c|}{ GCS } \\
\hline $9-12$ & $10(66.7 \%)$ & 7 (11.9\%) & $x^{2}=17.32$ & $<0.001^{* *}$ \\
\hline$>12$ & $5(33.3 \% \%)$ & $52(88.1 \%)$ & & \\
\hline \multicolumn{5}{|l|}{ NIHSS } \\
\hline$<5$ (minor stroke) & 0 & $10(16.9 \%)$ & $x^{2}=34.54$ & $<0.001^{* *}$ \\
\hline 5-15 (moderate stroke) & $2(13.3 \%)$ & $39(66.1 \%)$ & & \\
\hline 16-20 (moderate to severe stroke) & $6(40 \%)$ & $9(15.3 \%)$ & & \\
\hline 21-42 (severe stroke) & $7(46.7 \%)$ & $1(1.7 \%)$ & & \\
\hline
\end{tabular}

$T$ Student $T$ test, $X^{2}$ chi-square test, $M$ mean, SD standard deviation, TIA transient ischemic attack, GCS Glasgow Coma Scale

*Significant $(P<0.05)$

Finally, we found that patients with delirium had high mortality and lower BI and these results were statistically significant (Table 6).

\section{Discussion}

Stroke is one of the most frequent causes of death and disability worldwide and has significant clinical and socioeconomic impact [15]. The World Health Organization (WHO) refers to stroke as the incoming epidemic of the twenty-first century $[16,17]$. The outcome of stroke depends on several factors: the stroke itself, initial treatment,

Table 3 Delirium frequency according to type of stroke

\begin{tabular}{lllll}
\hline Type of stroke & \multicolumn{2}{l}{ Delirium } & \multirow{2}{*}{$X^{2}$} & $P$ \\
\cline { 2 - 4 } & Present N=15 & Absent N=59 & & \\
\hline Ischemic stroke & $7(46.7 \%)$ & $43(72.8 \%)$ & 6.97 & $0.03^{*}$ \\
Intracerebral hemorrhage & $7(46.7 \%)$ & $9(15.3 \%)$ & & \\
Subarachnoid hemorrhage & $1(6.6 \%)$ & $7(11.9 \%)$ & & \\
\hline
\end{tabular}

$x^{2}$ chi-square test

${ }^{*}$ Significant $(P<0.05)$ early rehabilitation, the early detection, and prevention of complications [5].

Delirium is a multifactorial neuropsychiatric disorder with definite predisposing and precipitating factor [18] and is one of the most common complications that older patients develop affecting up to $30 \%$ of all older medical hospitalized patients [19].

This study included 74 acute stroke patients, $54.1 \%$ of our patients were males and $45.9 \%$ were females. This was in agreement with other studies that reported males were more vulnerable to stroke than females [20-22].

Regarding the medical history of stroke patients, in this study, hypertension and diabetes mellitus were the most important risk factors of acute stroke with the highest population-attributable risk at $71.6 \%$ and $40.5 \%$, respectively; this was in agreement with many studies [23-25].

As regards the incidence of delirium in acute stroke patients, our study showed that the incidence of delirium among stroke patients was about $20.3 \%$. The prevalence of post stroke delirium is widely discrepant in the 
Table 4 Relationship between incidence of delirium and infarction subtypes in studied ischemic stroke patients according to TOAST criteria

\begin{tabular}{llll}
\hline Infarction subtypes & Delirium & & $x^{2}$ \\
\cline { 2 - 4 } & Present $N=7,(\%)$ & Absent $N=43,(\%)$ & 10.2 \\
LAA & $1(14.3 \%)$ & $18(41.9 \%)$ & $0.036^{*}$ \\
SAO & $1(14.3 \%)$ & $12(27.9 \%)$ & $7(16.3 \%)$ \\
Cardio-embolic & $5(71.4 \%)$ & $5(11.6 \%)$ \\
Undetermined etiology & 0 & $1(2.3 \%)$ & \\
Other determined etiology & 0 &
\end{tabular}

$X^{2}$ chi-square test, $L A A$ large-artery atherosclerosis, $S A O$ small-artery occlusion

*Significant $(P<0.05)$

various studies, ranging between 10\% [5] and 48\% [26]. This wide range of prevalence of delirium across studies could be due to the use of different criteria and assessment instruments for delirium, different inclusion and exclusion criteria, and different age groups included, sample size, and where and how the patients with stroke were treated [5].

Regarding age, we found that patients who developed delirium were older with mean age of $68.6 \pm 9.6$. This was in agreement with other studies [5, 26-31]. However, Oldenbeuving and colleagues [32] and Melkas and colleagues [32] found that age was not an independent risk factor for delirium. Several factors may precipitate delirium in higher age, most probably due to physiological loss of cholinergic reserve with aging.

As regards sex and incidence of delirium, no significant difference was found between male and female stroke patients. This is in agreement with previous studies [5, 29-33].

Table 5 Relationship between incidence of delirium and radiological finding in studied stroke patients

\begin{tabular}{clllll}
\hline & \multicolumn{2}{l}{ Delirium } & & $X^{2}$ & $P$ \\
\cline { 2 - 3 } & $\begin{array}{l}\text { Present } \\
N=7\end{array}$ & $\begin{array}{l}\text { Absent } \\
N=43\end{array}$ & & \\
\cline { 1 - 2 } Oxfordshire classification & & & & \\
TACl & $4(57.1 \%)$ & $4(9.3 \%)$ & 13 & $0.005^{*}$ \\
PACl & $1(14.3 \%)$ & $21(48.8 \%)$ & & \\
LACl & 0 & $12(27.9 \%)$ & & \\
POCl & $2(28.6 \%)$ & $6(14 \%)$ & & \\
Laterality of stroke & & & & \\
Right hemispheric & $11(73.3 \%)$ & $21(35.6 \%)$ & 7.96 & $0.047^{*}$ \\
Left hemispheric & $1(6.7 \%)$ & $21(35.6 \%)$ & & \\
Brainstem-cerebellum & $2(13.3 \%)$ & $8(13.5 \%)$ & & \\
No laterality & $1(6.7 \%)$ & $9(15.3 \%)$ & &
\end{tabular}

$x^{2}$ chi-square test, TACl total anterior circulation infarction, $P A C l$ partial anterior circulation infarction, $L A C l$ lacunar infarction, $P O C I$ posterior circulation infarction

*Significant $(P<0.05)$
We found that there was no significant relationship between incidence of delirium and certain risk factor of stroke (hypertension, diabetes mellitus, previous stroke, TIA, and cardiac diseases). This was in agreement with previous studies $[26,30]$. However, this was in disagreement with other studies that found delirium was significantly less prevalent in hypertensive patients [18] and smokers [28] and higher among stroke patients with cardiac disease [5].

Regarding the conscious level GCS at admission, we found highly significant relationship between the development of delirium and lower GCS at admission. Similar findings were obtained by other studies $[29,30]$.

Regarding NIHSS, delirious patients had higher NIHSS at admission. A highly significant relationship was found between the development of delirium and presence of severe neurological impairment at admission (NIHSS > 15). This was in agreement with results carried out by [32, 34]. Lower GCS and higher NIHSS at admission have been used as predictors of stroke severity. Severe strokes are more likely to be associated with medical complications, which by themselves could precipitate delirium [31].

Regarding incidence of delirium and type of stroke, we found that delirium is more prevalent in patients with cerebral hemorrhage compared to patients with ischemic stroke. This was in line with previous studies $[26,29,30$, 34].

Concerning the incidence of delirium and stroke subtypes according to TOAST criteria, we found that patients with cardio-embolic stroke type were more likely to develop delirium. While Oldenbeuving et al. [32]

Table 6 Relationship between incidence of delirium and outcome of studied patients

\begin{tabular}{lllll}
\hline Outcome & Delirium & & $\begin{array}{l}\text { Test of } \\
\text { significance }\end{array}$ & $P$ \\
\cline { 2 - 5 } & Present $N=15$ & Absent $N=59$ & \\
\hline Mortality (N\%) & $5(33.3 \%)$ & $4(6.8 \%)$ & $X^{2}=5.6$ & $0.017^{*}$ \\
Bl (M \pm SD) & $7.4 \pm 4.9$ & $13.5 \pm 5$ & $T=3.58$ & $>0.001^{* *}$ \\
\hline
\end{tabular}

$B$ Barthel Index

*Significant $(P<0.05)$ 
found that delirium was more frequent in patients with large-vessel stroke, other studies did not find an association between stroke etiologies defined according to TOAST criteria and incidence of delirium [35].

In the current study, the Oxfordshire classification criteria of cerebral infarction were used, and we found that delirium was more likely to occur in patients with a TACI. This was in agreement with several studies [30, 31, 33]. While Nicolai and Lazzarino [36] found that incidence of delirium was higher in patients with lesions of posterior cerebral artery territory, moreover, other studies $[5,28]$ found no significant association between lesion type or location and the development of delirium. Regarding our results showing that delirium is more prevalent in patients with TACI lesions and of cardio-embolic etiology, this is may be because such lesions are often larger, and hence, the findings may have been a reflection of stroke severity rather than the effect of its etiology [3].

Regarding the location of stroke lesion and development of delirium, our study disclosed that delirium was more frequent after hemispherical strokes. This was inconsistent with the results of Caeiro et al. [29] who found no significant difference between right and left hemispherical lesions. In our study, we found a significant association between the development of delirium and right hemispherical lesions. This was in agreement with the results carried out by other studies [32, 37-39]. However, other studies [36, 40] reported that delirium was more frequent with left-sided lesions. The right hemisphere has a critical role in spatial, bodily perception and orientation [41, 42] and plays a major role in perceiving emotion [42]. Disturbance of both spatial and emotional orientation might increase the likelihood of misinterpretation of the environment, leading to a higher risk of delirium [32].

Regarding the outcome of delirious patients, we found that those who experienced delirium had unfavorable outcomes in the form of increased hospital stay and higher mortality mainly in hospital mortality. In addition, we also found functional outcomes measured with BI to be worse after delirium. Similar findings were consistently reported by many previous studies $[26,27$, 29-32]. The latter found that 1-month mortality was not significantly different between patients with and without delirium, although long-term (6 months and 12 months post stroke) mortality was higher in patients with delirium. Henon and colleagues [28] reported that there is no significant difference in inpatient mortality between delirious and non-delirious patients. The heterogeneity in inpatient mortality could be explained by the different timeframes of delirium onset and differences in management of stroke patients [43].

\section{Conclusion}

Delirium occurs in almost $20.3 \%$ of acute stroke patients. Factors associated with the development of post stroke delirium included old age, higher NIHSS at admission, intracerebral hemorrhage, right-sided hemisphenic stroke, total anterior circulation infarction, and cardio-embolic ischemic stroke. Patients with delirium had larger hospital stay, higher long-term mortality, and a worse functional outcome.

\section{Recommendations}

It is recommended that all stroke units should have screening protocols for detection, managing patients with delirium and preventing delirium in high-risk patients especially elderly patients could improve the prognosis.

We also recommend future research to study whether early identification of stroke patients at risk for delirium would result in a better outcome and to identify effective interventions that improve the outcome for patients with delirium.

\begin{abstract}
Abbreviations
Bl: Barthel Index; CT: Computed tomography; DM: Diabetes mellitus; DSMIV: Diagnostic and Statistical Manual of Mental Disorders, 4th Edition; GSC: Glasgow Coma Scale; HTN: Hypertension; LACI: Lacunar anterior circulation infarction; MMSE: Mini Mental State Examination; NIHSS: National Institutes of Health Stroke Scale; PACl: Partial anterior circulation infarction; POCI: Posterior circulation infarction; SD: Standard deviation; SPSS: Statistical Package for the Social Sciences; TACI: Total anterior circulation infarction; TIA: Transient ischemic attack; TOAST: Trial of Org 10172 in Acute Stroke Treatment; $T$ test: Student's $T$ test; WHO: World Health Organization; $X^{2}$ : Chisquare
\end{abstract}

\section{Acknowledgements}

Not applicable.

\section{Funding}

This study received no funding from any public, commercial, or not-for profit sectors.

\section{Availability of data and materials}

The paper is a part of thesis conducted in the Faculty of Medicine, Zagazig University, and approved by its ethical committee. The data can be publicly available at the Faculty of Medicine, Zagazig University.

\section{Disclosures}

The manuscript has been read and approved by all the authors.

\section{Authors' contributions}

MAZ was responsible for the design of the study and guidance and follows up the final revision. DAE was responsible for the guidance, follows up the final revision, and prepares the paper's final revision. BMR was responsible for writing the manuscript and guidance and follows up the final revision. HA was responsible for the practical work and was involved in the design of the study. All authors read and approved the final manuscript.

\section{Ethics approval and consent to participate}

The study protocol was approved by the ethics committee of the faculty of Medicine of Suez Zagazig University, 7 June, 2015, registration number is 2123.

The purpose of the study was explained, and an informed written consent was taken before taking any data or doing any investigations.

The participants were informed that their participation was voluntary and that they could withdraw from the study at any time without consequences. 
The participants were assured that all data will be considered confidential and will not be used outside this research. At the end of this study, records will be destroyed appropriately.

\section{Consent for publication}

All participants had signed an informed consent to participate and for the data to be published.

\section{Competing interests}

The authors declare that they have no competing interests.

\section{Publisher's Note}

Springer Nature remains neutral with regard to jurisdictional claims in published maps and institutional affiliations.

Received: 7 October 2017 Accepted: 13 January 2019

Published online: 20 February 2019

\section{References}

1. Macrez R, Ali C, Toutirais O, Le Mauff B, Defer G, Dirnagl U, Vivien D. Stroke and the immune system: from pathophysiology to new therapeutic strategies. Lancet Neurol. 2011;10:471-80.

2. American Psychiatric Association Delirium, Dementia and Amnestic and Other Cognitive Disorders. Diagnostic and statistical manual of mental disorders, 4th edition, text reviewed. Washington. DC: American Psychiatric Press; 2002. p. 153-80.

3. Carin-Levy G, Mead GE, Nicol K, Rush R, van Wijck F. Delirium in acute stroke: screening tools, incidence rates and predictors: a systematic review. J Neurol. 2012;259(8):1590-9.

4. Makin SDJ, Wardlaw J. Predicting delirium after a stroke. J Neurol Neurosurg Psychiatry. 2013;85:357

5. Dahl MH, Ronning OM and Thommessen B. Delirium in acute strokeprevalence and risk factors. Acta Neurol Scand. 2010;190(Suppl):39-43.

6. Klimiec E, Dziedzic T, Kowalska K, Szyper A, Pera J, Potoczek P, Slowik A, Klimkowicz-Mrowiec A. PRospective Observational POLIsh Study on post-stroke delirium (PROPOLIS): methodology of hospital-based cohort study on delirium prevalence, predictors and diagnostic tools. BMC Neurol. 2015;15:94.

7. Folstein MF, Folstein SE, McHugh PR. 'Mini mental state'. a practical method for grading the cognitive state of patients for the clinician. J Psychiatr Res. 1975;12(3):189-98.

8. Odderson IR. The National Institutes of Health Stroke Scale and its importance in acute stroke management. Phys Med Rehabil Clin N Am. 1999:10:787-800

9. Fonarow GC, Saver JL, Smith EE, Broderick JP, Kleindorfer DO, Sacco RL, Pan W, Olson DM, Hernandez AF, Peterson ED, Schwamm LH. Relationship of National Institutes of Health Stroke Scale to 30-day mortality in Medicare beneficiaries with acute ischemic stroke. J Am Heart Assoc. 2012:1:42-50.

10. Adams HP, Bendixen BH, Kappelle $L$, Love BB. Classification of subtype of acute ischemic stroke. Definitions for use in a multicenter clinical trial. TOAST. Trial of Org 10172 in Acute Stroke Treatment. Stroke. 1993;24:35-41.

11. Bamford J, Sandercock P, Dennis M, Burn J, Warlow C. Classification and natural history of clinically identifiable subtypes of cerebral infarction. Lancet. 1991;337:1521-6.

12. American Psychiatric Association. Diagnostic and statistical manual of mental disorders. 4th ed. Washington, DC: American Psychiatric Association; 1994

13. Collin C, Wade DT, Davies S, Horne V. The Barthel ADL Index: a reliability study. Int Disabil Stud. 1988:10:61-3.

14. Levesque R. SPSS programming and data management: a guide for SPSS and SAS users. 4th ed. Chicago III: SPSS Inc.; 2007.

15. Wang Q, Tang XN, Yenari MA. The inflammatory response in stroke. J Neuroimmunol. 2007;184(1-2):53-68.

16. O'Donnell M, Xavier D, Diener C. Rationale and design of INTERSTROKE: a global case-control study of risk factors for stroke. Neuroepidemiology. 2010:35:36-44.

17. Sarikaya H, Ferro J, Arnold M. Stroke prevention - medical and lifestyle measures. Eur Neurol. 2015:73:150-7.

18. Dostović Z, Smajlović D, Dostović E, Ibrahimagić OĆ. Stroke and disorders of consciousness. Cardiovasc Psychiatry Neurol. 2012:2012:429108.

19. Young J, Inouye S. Delirium in the older people. Br Med J. 2007;334:842-6.
20. Abdel Ghani AA, Zaitoun AM, Gawish HH, Abo Warda MH. Prognostic value of D-dimer in diffusion weighted-MRI defined early ischemic stroke recurrence. Egypt J Neurol Psychiat Neurosurg. 2011;48(3):215-22.

21. El Tallawy HN, Farghaly WM, Rageh TA, Shehata GA, Badry R, Metwally NA, Moselhy EA, Hassan M, Sayed MA, Waris AA, Hamed Y, Shaaban I, Hamed MA, Kandil MR. Door-to-door survey of major neurological disorders (project) in Al Quseir City, Red Sea Governorate, Egypt. Neuropsychiatr Dis Treat. 2013:9:767-71.

22. Khedr EM, Fawi G, Abdela M. Prevalence of ischemic and hemorrhagic strokes in Qena Governorate, Egypt: community-based study. J Stroke Cerebrovasc Dis. 2014;23(7):1843-8.

23. El Tallawy HN, Farghaly WM, Rageh TA, Shehata GA, Metwaly NA, Elftoh NA, Hegazy AM, Moselhy EA, Rayan L, Al Fawal BM, Hamed MA. Epidemiology of major neurological disorders project in Al Kharga district, New Valley, Egypt. Neuroepidemiology. 2010:35:291-7.

24. Park YW, Koh EJ, Choi HY. Correlation between serum D D level and volume in acute ischemic stroke. J Korean Neurosurg Soc. 2011;50(2):89-94.

25. Yang XY, Gao S, Ding J, Chen Y, Zhou XS, Wang JE. Plasma D-dimer predicts short-term poor outcome after acute ischemic stroke. PLoS One. 2014:9(2):1-7.

26. Gustafson Y, Olsson T, Eriksson S, Asplund K, Bucht G. Acute confusional states (delirium) in stroke patients. Cerebrovasc Dis. 1991;1:257-64.

27. Gustafson Y, Olsson T, Asplund K, Hagg E. Acute confusional state (delirium) soon after stroke is associated with hypercortisolism. Cerebrovasc Dis. 1993; 3:33-8.

28. Henon H, Labert F, Durieu I, Godefroy O, Lucas C, Pasquier F, Leys D. Confusional state in stroke: relation to pre-existing dementia, patient characteristics, and outcome. Stroke. 1999;30:773-9.

29. Caeiro L, Ferro JM, Albuquerque R. Delirium in the first days of acute stroke. J Neurol. 2004;251:171-8.

30. Sheng AZ, Shen Q, Cordato D, Zhang YY, Chan DKY. Delirium within three days of stroke in a cohort of elderly patients. J Am Geriatr Soc. 2006;54: 1192-8.

31. McManus J, Pathansali R, Hassan H, Ouldred E, Cooper D, Stewart R, Macdonald A, Jackson S. The course of delirium in acute stroke. Age Ageing. 2009;38:385-9.

32. Oldenbeuving AW, de Kort PL, Jansen BP, Algra A, Kappelle $L$, Roks $G$. Delirium in the acute phase after stroke: incidence, risk factors, and outcome. Neurology. 2011;76:993-9.

33. Melkas S, Laurila JV, Vataja R, Oksala N, Jokinen H, Pohjasvaara T, Leppävuori A, Kaste M, Karhunen PJ, Erkinjuntti T. Post-stroke delirium in relation to dementia and long-term mortality. Int J Geriatr Psychiatry. 2012;27:401-8.

34. Kostalova M, Bednarik J, Mitasova A, Dusek L, Michalcakova R, Kerkovsky M, Kasparek T, Jezkova M, Balabanova P, Vohanka S. Towards a predictive model for post-stroke delirium. Brain Inj. 2012;26:962-71.

35. Henon $H$, Leys D. "Delirium in stroke patients." neuropsychiatric symptoms of cerebrovascular diseases. London: Springer; 2013. p. 3-29.

36. Nicolai A, Lazzarino LG. Acute confusional states secondary to infarctions in the territory of the posterior cerebral artery in elderly patients. Ital J Neurol Sci. 1994;15:91-6.

37. Schmidley JW, Messing RO. Agitated confusional states in patients with right hemisphere infarctions. Stroke. 1984;15:883-5.

38. Dunne JW, Leedman PJ, Edis RH. Inobvious stroke: a cause of delirium and dementia. Aust NZ J Med. 1986:16:771-8.

39. Mori E, Yamadori A. Acute confusional state and acute agitated delirium: occurrence after infarction in the right middle cerebral artery territory. Arch Neurol. 1987:44:1139-43

40. Shih HT, Huang WS, Liu CH, Tsai TC, Lu CT, Lu MK, Chen PK, Tseng CH, Jou SB, Tsai CH, Lee CC. Confusion or delirium in patients with posterior cerebral arterial infarction. Acta Neurol Taiwanica. 2007:16:136-42.

41. Kaplan J, Hier DB. Visuospatial deficits after right hemisphere stroke. Am J Occup Ther. 1982:36:314-21.

42. Heilman KM, Bowers D, Valenstein E, Watson RT. The right hemisphere: neuropsychological functions. J Neurosurg. 1986;64:693-704.

43. Shi Q, Presutti R, Selchen D, Saposnik G. Delirium in acute stroke: a systematic review and meta-analysis. Stroke. 2012;43:645-9. 